\title{
ESTUDO SEMÂNTICO-DISCURSIVO DA REFERÊNCIA TEXTUAL SOB A PERSPECTIVA DA LINGUÍSTICA SISTÊMICO-FUNCIONAL
}

\author{
SEMANTIC-DISCURSIVE STUDY OF THE TEXTUAL REFERENCE UNDER THE \\ PERSPECTIVE OF SYSTEMIC FUNCTIONAL LINGUISTICS
}

\author{
Luciane Sippert ${ }^{1}$, Lucia Rottava ${ }^{2}$
}

\begin{abstract}
RESUMO: $O$ presente artigo, fundamentado na Linguística Sistêmico-Funcional (HALLIDAY, 1978; HALLIDAY e MATTHIESSEN, 2004, 2009 e 2014), aborda a referência com base na metafunção textual. Nosso objetivo foi explicitar os sistemas discursivos de identificação e periodicidade, a fim de contribuir para a reflexão relacionada ao estudo do texto no Brasil, em uma perspectiva sistêmico-discursiva (MARTIN e ROSE, 2007). Trata-se de um estudo de natureza qualitativa e interpretativa, realizado a partir da análise de cinco textos do gênero resenha escritos em contexto acadêmico. Esta análise contemplou a metafunção textual proporcionando o entendimento da progressão textual, a partir dos processos de identificação e periodicidade. Os tipos de referências e de estrutura temática presentes nos textos levou a conclusão de que os alunos têm um conhecimento implícito destas estratégias de construção textual, no entanto, requerem um trabalho sistematizado para explorar as potencialidades da linguagem a fim de contribuir para o aprimoramento do letramento acadêmico.
\end{abstract}

PALAVRAS-CHAVE: Linguística Sistêmico-Funcional; referência; identificação; periodicidade.

\begin{abstract}
This paper, based on the Systemic-Functional Linguistics (HALLIDAY, 1978; HALLIDAY and MATTHIESSEN, 2004, 2009 and 2014), focus on the reference based on textual metafunction. The objective was to explain the discursive systems of identification and periodicity, in order to contribute to the reflection related to the study of the text in Brazil (MARTIN and ROSE, 2007). The study is qualitative and interpretative, based on the analysis of texts written in a academic context. The corpus was formed by five texts of the genre review. The analysis contemplated the textual metafunction providing the understanding of the textual progression, from the semantic-discursive identification and periodicity processes. References and thematic structure present in the texts led to the conclusion that students have an implicit knowledge of these textual construction strategies, however, they require a systematized work to explore the potentialities of language in order to contribute to the improvement of academic literacy.
\end{abstract}

KEYWORDS: Systemic-Functional Linguistics; reference; identification; periodicity.

\footnotetext{
${ }^{1}$ Doutora em Letras pela Universidade Federal do Rio Grande do Sul, UFRGS (2017). Docente adjunta de Língua Portuguesa da UERGS nos cursos de graduação e pós-graduação.

2 Mestra em Letras pela Universidade Federal do Rio Grande do Sul (1995). Doutora em Linguística Aplicada pela Universidade Estadual de Campinas (2001) e Pós-Doutorado em Linguística Aplicada na University of London. Docente Professor Adjunto na UFRGS na graduação e na pós-graduação.
} 


\section{Introdução}

A referência é a base da significação, a fonte contextual da produção de sentidos que viabiliza a construção de referentes. Os estudos que abordam questões relacionadas à referência têm origem no trabalho seminal de Halliday e Hasan (1976), que propõem cinco tipos de mecanismos coesivos, quais sejam: referência, elipse, substituição, conjunção e coesão lexical. Pela relevância que a noção de referência tem na organização textual, vários estudiosos têm direcionado o foco de seus estudos para este tema. Alguns numa perspectiva sociointeracionista (APOTHÉLOZ, 1995 e 2001; APOTHÉLOZ e CHANET, 2003; CHAROLLES, 1999; MONDADA E DUBOIS, 2001, 2003 e 2005), que remete aos trabalhos da Linguística Textual, outros numa perspectiva sistêmico-discursiva (HALLIDAY e MATTHIESSEN, 2004, 2009 e 2014; THOMPSON, 2014; MARTIN, 1992; MARTIN e ROSE, 2007; ROSE e MARTIN, 2012), embasados na Linguística Sistêmico-Funcional (doravante, LSF). Neste artigo, focaliza-se a referência sob a abordagem sistêmico-discursiva, em vista da carência de estudos nessa área (VIAN JR.; MENDES, 2015; NUNES, 2010). Assim, é objetivo explicitar os sistemas discursivos de identificação e periodicidade, a fim de compreender a organização textual numa perspectiva sistêmico-discursiva.

Segundo Halliday e Matthiessen (2009), a metafunção textual é responsável pela expressão da estrutura e formato do texto, pela organização dos recursos gramaticais e está relacionada ao contexto de situação/registro e à variável modo ${ }^{l}$. As variáveis do contexto de situação de campo, relações e modo podem ser identificadas nos textos a partir de determinados elementos linguísticos e estão intrinsecamente relacionadas às funções que a linguagem desempenha. Assim, a partir da análise da metafunção textual é possível entender como se dá a relação entre os aspectos lexicogramaticais e organizacionais que envolvem identificação e a periodicidade.

Este estudo pode ser caracterizado como uma pesquisa qualitativa-interpretativista. Qualitativa por ter como sua preocupação maior a descrição, compreensão e interpretação dos fenômenos observados em um contexto específico de uso da língua (cf. BOGDAN E BIKLEN, 1994) e interpretativista por recorrer a uma grade de categorias estabelecidas com base nos dados que foram coletados e analisados, com a finalidade de compreender o processo de ensinar/aprender línguas (CAVALCANTE E MOITA LOPES, 1991; MOITA LOPES, 2001). Assim, o presente trabalho, de cunho qualitativo e interpretativo, volta-se à análise de cinco textos do gênero resenha escritos em contexto acadêmico ${ }^{2}$, os quais foram analisados a partir dos sistemas discursivos de identificação e periodicidade, com base na 
LSF. Teoria essa que aborda a linguagem como processo social e emprega uma metodologia analítica, permitindo assim a descrição detalhada e sistemática dos padrões da linguagem em uso (EGGINS, 1994 e 2004).

O presente artigo está organizado em três seções. Na primeira, apresenta-se o conceito geral de referência na perspectiva sistêmico-discursiva e os sistemas semântico-discursivos. $\mathrm{Na}$ segunda, apresenta-se o sistema de identificação e suas principais categorias contextualizadas em situações reais de uso da língua. Na terceira seção, aborda-se o sistema de periodicidade.

\section{Referência: perspectiva sistêmico-discursiva}

O conceito de referência postulado por Halliday e Hasan (1976) diz respeito a certos itens que não podem ser interpretados por si próprios, mas a partir da relação que estes estabelecem com alguém ou alguma coisa, como afirmam:

Há certos itens em todas as línguas que têm a propriedade de referência, no sentido específico em que estamos usando o termo aqui; quer dizer, em vez de serem interpretados semanticamente, por si próprios, eles fazem referência a algum outro elemento para a sua interpretação (HALLIDAY; HASAN, 1976, p. 31) ${ }^{3}$.

Para os autores, a interpretação do referente está diretamente ligada à significação linguística. O sentido pode ser inferido a partir das referências exofóricas, que têm a ver com o contexto situacional, ou endofóricas, cuja significação está dentro do próprio texto e pode retomar um termo já expresso no texto de forma anafórica (refere-se a algo que já foi dito) ou catafórica (quando antecipa algo que será expresso mais adiante no texto). De modo geral, os autores apresentam três tipos de referência: (a) pessoal (pronomes pessoais e possessivos); (b) demonstrativa (pronomes demonstrativos e advérbios de lugar) e (c) comparativa (por via indireta, através de identidades ou similaridades). Para compreender esse funcionamento, nos exemplos ${ }^{4}$ a seguir, ilustram-se alguns desses tipos de referência, conforme classificação de Halliday e Hasan (1976):

(01) Por fim, depois de toda essa análise do filme, [nós] vimos todos os processos dos capítulos que estudamos. (T2_PED_SFP). (Referência exofórica).

(02) O garoto se torna órfão. Ele passa a morar escondido numa estação de trem. (T4_PED_OSO).(Referência anafórica).

(03) O Boletim apresenta três artigos, Os Agrotóxicos e o Direito de Escolha dos Cidadãos, Levantamento dos Agrotóxicos Usados no Estado do Rio Grande do Sul por Bacia Hidrográfica, Avaliação dos Registros de Intoxicação por Agrotóxicos no Rio Grande do Sul. (T5_GA_TP). (Referência catafórica).

(04) Com a chegada de Erin Gruwell a nova professora da turma com o seu entusiasmo, dedicação e com muita motivação ela fez a diferença. (T2_PED_SFP). (Referência anafórica). 
No exemplo (01), o referente "[nós]" está elíptico, mas é recuperável pela desinência do verbo e diz respeito ao autor e à professora (sua leitora em potencial), podendo-se presumir ainda que este termo pode estar se referindo a todos os alunos da turma, ou seja, trata-se de uma referência exofórica. Por sua vez, a referência endofórica é observável nos demais exemplos, ou seja, em (02), o pronome pessoal "ele" retoma o referente "O garoto" apresentados anteriormente no texto, por anáfora; em (03), o sintagma nominal "três artigos", e por catáfora em (04), cujos referentes "a nova professora da turma" e "ela" recuperam anaforicamente o referente "Erin Gruwell". Constituem-se elementos que funcionam como coesão textual e, portanto, de acordo com Halliday e Matthiessen (2004), é pela a referência, como um dos dois tipos principais de coesão, que "se refere aos valores atribuídos a elementos do discurso que orientam os falantes e ouvintes no processamento desses elementos" (p. 549).

O status de um texto no sistema de referência é o de identificabilidade: faz o falante/autor julgar se um determinado elemento pode ser recuperado ou identificado pelo ouvinte/leitor no decorrer deste. Se ele for apresentado como identificável, em seguida, o ouvinte/leitor terá de recuperar a identidade de algum lugar; por outro lado, se ele for apresentado como não-identificável, então, o ouvinte/leitor terá que o estabelecer uma nova interpretação do texto ${ }^{5}$

De acordo com Vian Jr. e Mendes (2015), o entendimento de coesão apresentado por Halliday e Hasan (1976) é reformulado por Martin (1992), que propõe um olhar para além de um conjunto lexicogramatical, contemplando um conjunto de sistemas semântico-discursivos, em um nível mais abstrato, que compreenderia seis sistemas: identificação, negociação, conjunção, ideação, periodicidade e avaliatividade, apresentados na Figura 1, a seguir:

\begin{tabular}{|c|c|c|c|}
\hline \multicolumn{2}{|c|}{ Sistema semântico-discursivo } & \multicolumn{2}{|c|}{ Metafunção } \\
\hline Identificação & Rastrear pessoas e coisas & \multirow[b]{2}{*}{ Textual } & \multirow{2}{*}{ Organizar os textos } \\
\hline Periodicidade & Fluxo de informação & & \\
\hline Negociação & Promover trocas & \multirow[b]{2}{*}{ Interpessoal } & \multirow{2}{*}{$\begin{array}{l}\text { Deflagrar relações } \\
\text { sociais }\end{array}$} \\
\hline Avaliatividade & Negociar atitudes & & \\
\hline Conjunção & Conectar eventos & \multirow[b]{2}{*}{ Ideacional } & \multirow{2}{*}{$\begin{array}{l}\text { Representar a } \\
\text { experiência }\end{array}$} \\
\hline Ideação & Representar a experiência & & \\
\hline
\end{tabular}

Figura 1- Relação dos sistemas discursivos/metafunções

Fonte: Martin e Rose (2007), adaptado por Vian Jr. e Mendes (2015).

A ênfase neste estudo são os processos de organização textual e as relações estabelecidas na metafunção textual. Assim, nas seções a seguir são apresentados os sistemas 
discursivos de identificação e de periodicidade, com exemplificação das principais categorias identificadas nos textos analisados.

\section{Identificação: rastreamento de participantes}

O sistema de identificação, como salientam Martin e Rose (2007), diz respeito ao "rastreamento dos participantes - com a introdução de pessoas e coisas no texto e como mantê-los nele. Esses recursos textuais contemplam o modo como o texto faz sentido para o leitor pelo rastreamento de identidades" (p.155) ${ }^{6}$. Nessa perspectiva, os autores descrevem possibilidades de identificação de pessoas e coisas no texto, como apresentá-las, retomá-las ou mantê-las, de modo que se possa traçar o caminho percorrido pelo sentido no texto, usando os recursos de: apresentação ${ }^{7}$ (presenting) - apresentação de uma referência desconhecida; pressuposto (presuming) - presunção ou fazer referência a algo que está sendo retomado no texto; posse (possessive) - indicação de posse, e comparação (comparative) - comparação entre dois referentes. Os dois últimos recursos podem ser usados tanto para apresentar como para retomar algo que já tenha sido mencionado no texto.

Para compreender melhor esses recursos, o exemplo (05) mostra o funcionamento dos principais recursos de identificação, manutenção e retomada de participantes no discurso.

\section{(05) Resenha do Filme Escritores da Liberdade}

O filme que se passa no ano de 1994 relata histórias de $(1)^{8}$ jovens em (4) uma realidade impactante de uma cidade (4) chamada Long Beach, (4) localizada nos Estados Unidos que é reconhecido como o país da liberdade. (1) Todos eles tinham várias realidades diferentes, e lutavam por igualdade, respeito, e não tinham o menor interesse em estar na escola, (1) totalmente desmotivados, e com famílias com histórias muito fortes.

(4) Nesta cidade vivia (2) uma jovem chamada Eva, que desde muito pequena (2) [ela] presenciou cenas de violência com (2) seus familiares, até mesmo viu (2) seu pai ser preso por "policiais" dentro de (2) sua própria casa. (2) Eva quando grande já no $2^{\circ}$ ano do Ensino Médio, era da turma que tinha apenas (1) alunos que saíram do reformatório, problemáticos e todos com realidades extremamente difíceis. Com a chegada de (3) Erin Gruwell (3) a nova professora da turma (3) com o seu entusiasmo, dedicação e com muita motivação (3) ela fez a diferença, mesmo com todos duvidando de (3) sua capacidade e mesmo depois de todos os obstáculos encontrados, (3) ela persistiu.

(3) A professora não desistiu e (3) Ø [ela] continuou as tentativas de conquistar a atenção (1) dos alunos, ela entra na realidade (1) deles, (1) os deixa escrever sobre (1) seus problemas e (1) sua vida, assim, $\varnothing$ [ela] conhece (1) a realidade de cada um. Então no decorrer do ano letivo as novidades que (3) a senhora Gruwell preparava, mesmo sem apoio da direção escolar e de alguns professores, eram cada vez mais esperadas (1) pelos alunos, (3) $\varnothing$ [ela] mostrou que com carinho, companheirismo e atenção,(1) eles tinham uns aos outros, assim como vimos nos capítulos estudados, como ser um bom professor e como ele deve de fato agir. No final do ano, a professora deu a ideia de escreverem os (5) diários, onde (sic) foram publicados por diversos jornais, sempre (1) os motivando.

Enfim, tiveram a oportunidade de publicar (5) o Diário dos Escritores da Liberdade que contava (5) todas as (1) suas histórias, inclusive a de que muitos foram os 
primeiros de (2) suas famílias a entrarem em uma Faculdade, sendo (2) grandes vitoriosos pelos desafios que (2) [eles]percorrem até então. Isso foi tão significativo na vida (1) destes alunos que até hoje, (2) [eles] fazem trabalhos parecidos com outros jovens no Instituto dos Escritores da Liberdade e Fundação dos Escritores da Liberdade.

Por fim, depois de toda essa análise do filme, vimos todos os processos dos capítulos que estudamos. Mostrando-nos que um bom professor, vai sim, aplicar, textos, matérias, mas vai também saber como aplicar, e como mudar a realidade (2) dos alunos em sala de aula, aprendendo todos juntos. ${ }^{9}$ (T2_PED_SFP).

No exemplo (05), observa-se a introdução de cinco participantes principais: três pessoas (jovens, Eva e Erin Gruwell) e duas coisas (cidade e os diários). A primeira menção aos jovens é feita com a introdução de histórias de jovens. Na sequência, o autor descreve a história do filme e para isso não repete mais nenhuma vez a palavra "jovens", apenas a retoma por meio do processo de referência textual. Os recursos linguísticos de retomada usados foram: todos eles, totalmente desmotivados; alunos que saíram do reformatório, problemáticos e todos com realidades extremamente difíceis; dos alunos; deles; os (deixa); seus (problemas); sua (vida); a realidade de cada um; pelos alunos; eles; os (motivando); suas (histórias); destes alunos; suas (famílias); grandes vitoriosos; [eles] percorrem. Esses recursos de identificação que foram empregados para rastrear "jovens", estão identificados no referido exemplo pelo número (1).

Ainda no exemplo (05), observa-se na oração "O filme que se passa no ano de 1994 relata histórias de jovens", ao mencionar "histórias de jovens", embora se trate de um termo novo introduzido no texto, não está acompanhado de nenhum elemento determinativo - artigo definido ou indefinido, pois pressupõe que "histórias de jovens" seja do conhecimento compartilhado entre escritor/leitor.

Uma situação diferente ocorre no exemplo (06), no qual foi introduzida a participante Eva por meio de um artigo indefinido:

(06) Nesta cidade vivia uma jovem chamada Eva, que desde muito pequena $\varnothing$ [ela] presenciou cenas de violência com seus familiares, até mesmo $\varnothing$ [ela] viu seu pai ser preso por "policiais" dentro de sua própria casa. Eva quando grande já no $2^{\circ}$ ano do Ensino Médio, era da turma que tinha apenas alunos que saíram do reformatório, problemáticos e todos com realidades extremamente difíceis.

Similar ao inglês, conforme observado por Martin e Rose (2007), uma estratégia básica de introdução de pessoas no português é usar um artigo indefinido (um, uma, uns, umas). Em "uma jovem chamada Eva", ao usar "uma" percebe-se que é uma jovem desconhecida do leitor ou uma identidade nova que está sendo inserida no discurso. $\mathrm{Na}$ segunda vez que "Eva" aparece no texto, ela é retomada nominalmente, sem qualquer determinante, pois o leitor identifica quem ou de que referente está se tratando. Além disso, "Eva" é retomada pelos pronomes possessivos seus, seu, sua e três vezes de forma elíptica 
[ela]. A forma elíptica de retomada não é mencionada por Martin e Rose (2007), considerando que em inglês esse não é um recurso empregado no nível semântico para realizar a função de Tema sujeito. Halliday e Matthiessen (2004), por sua vez, referem-se à elipse (juntamente com a substituição), como uma ferramenta coesiva lexicogramatical, que estabelece conexões entre elementos textuais. Essa ferramenta indica continuidade, segundo os autores, "tornando possível suprimir partes de uma estrutura quando estas puderem ser presumidas através daquilo que antecede [no texto]"10 (HALLIDAY; MATTHIESSEN, 2004, p. 535). Neste caso, considera-se a elipse como um recurso de referência, pois está pressuposta na desinência do verbo.

A introdução dos participantes pode ser observada no exemplo (07):

(07) Com a chegada de Erin Gruwell a nova professora da turma com o seu entusiasmo, dedicação e com muita motivação ela fez a diferença, mesmo com todos duvidando de sua capacidade e mesmo depois de todos os obstáculos encontrados, ela persistiu.

A maneira como Erin Gruwell aparece a primeira vez no texto, no exemplo (07), identifica-se com o que Martin e Rose (2007) dizem tratar-se de uma aparente anomalia, pois esta não é introduzida por um artigo indefinido, como foi $E v a$, mas pelo próprio nome. Isso é feito em situações que o escritor presume que o seu leitor saiba de que pessoa/referente está se tratando. Como afirmam “(...) falantes/escritores fazem suposições do que ouvintes/leitores podem e não podem esperar para saber. Se a identidade de alguém é tão boa como dada então como referência presumida é usada, mesmo que essa pessoa não tenha sido mencionada antes" (MARTIN e ROSE, 2007, p. 163) ${ }^{11}$.

Erin Gruwell é retomada no decorrer do exemplo (05): por expressões que se referem ao tipo de pessoa que ela é: com o seu entusiasmo, dedicação e com muita motivação; pelo pronome ela duas vezes; pelo pronome elíptico $\varnothing$ [ela]; pelo pronome de tratamento Senhora Gruwell; pelo possessivo sua; e pelo epíteto a professora três vezes, sendo que na primeira vez aparece com os determinantes "nova" $e$ "da turma".

Na Figura 2, apresentam-se os recursos básicos para introduzir e rastrear pessoas no texto, a partir do texto T2_PED_SFP, transcrito em (05):

\begin{tabular}{|c|c|c|}
\hline (1) Jovens/alunos & (2) Eva & (3) Erin Gruwell \\
\hline todos eles; totalmente & [ela]; & a nova professora da turma; \\
desmotivados; dos alunos; & Seus (familiares); & A professora; [ela]; [ela]; a \\
deles; os (deixa); seus & Seu (pai); & senhora Gruwell; [ela]; seu \\
(problemas); sua (vida); & Sua (própria casa); & entusiasmo, dedicação e com \\
pelos alunos; eles; os & Eva; & (capacida motivação; ela; ela; sua \\
(motivando); suas (histórias); & [ela]. & \\
destes alunos. & & \\
\hline
\end{tabular}

Figura 2 - Rastreamento de pessoas no discurso 
Além das pessoas rastreadas no texto e explicitadas na Figura 2, observa-se também a introdução de coisas como uma cidade e os diários. No primeiro caso, "cidade" é mencionada a primeira vez no exemplo (05), acompanhada por um artigo indefinido "uma" e um sintagma nominal "realidade impactante de uma cidade". Essa estratégia segue o padrão já mencionado anteriormente, a partir dos pressupostos de Martin e Rose (2007). Já “diários” ao ser introduzido por um artigo definido "os", observa-se outra aparente anomalia, em consonância com os autores. Usualmente, a primeira menção que se faz a uma pessoa ou coisa no texto deveria ser usado um artigo indefinido (um, uma, uns, umas), somente na segunda vez que se faz menção ao termo já apresentado usar-se-ia o pronome definido (o, a, os, as). Entretanto, essa regra não se mantém em todos os casos, da mesma forma que em algumas situações usa-se o artigo indefinido "uma" para se referir a alguém ou alguma coisa já identificada. Isso pode ser ilustrado com a situação mencionada por Martin e Rose (2007, p. 162): "Minha história começa no final da adolescência como uma menina de fazenda ..."12. Neste caso, observa-se que a expressão "uma menina da fazenda" está sendo usada para descrever ou classificar uma pessoa e não para identificá-la. Assim como a identificação, o rastreamento ou retomada das coisas no discurso dá-se similarmente na forma como acontece com as pessoas. "Uma cidade" foi retomada por "chamada Long Beach", "localizada nos Estados Unidos" e "Nesta cidade".

O termo "os diários" foi retomado por "o Diário dos Escritores da Liberdade", "todas as suas histórias" e "trabalhos parecidos". É interessante observar que o autor do texto, ao trazer a referência "trabalhos parecidos", está recorrendo ao processo de comparação, que é estabelecido em relação aos diários mencionados anteriormente, sendo esta também uma forma de manutenção do sentido. Na Figura 3, apresentam-se os recursos básicos para introduzir e rastrear pessoas e coisas no texto apresentado em (05):

\begin{tabular}{|c|c|c|c|c|}
\hline Identificação de: & $\begin{array}{l}\text { Apresentação/ } \\
\text { Presenting }\end{array}$ & $\begin{array}{l}\text { Pressuposto/ } \\
\text { Presuming }\end{array}$ & $\begin{array}{c}\text { Possel } \\
\text { Possessive }\end{array}$ & $\begin{array}{l}\text { Comparação/ } \\
\text { comparative }\end{array}$ \\
\hline \multirow{3}{*}{$\begin{array}{l}y \\
\vdots \\
\vdots \\
2 \\
2\end{array}$} & $\begin{array}{c}(1) \\
\text { Jovens/alunos }\end{array}$ & $\begin{array}{l}\text { todos eles; totalmente desmotivados; } \\
\text { dos alunos; os (deixa); pelos alunos; } \\
\text { eles; os (motivando); destes alunos; } \\
\text { cada um }\end{array}$ & $\begin{array}{c}\text { deles } \\
\text { seus (problemas) } \\
\text { sua (vida) } \\
\text { suas (histórias) } \\
\end{array}$ & \\
\hline & (2) Eva & [ela]; Eva; [ela] & $\begin{array}{l}\text { seus (familiares); } \\
\text { seu (pai); sua } \\
\text { (própria casa) }\end{array}$ & \\
\hline & (3) Erin Gruwell & $\begin{array}{c}\text { a nova professora da turma; A } \\
\text { professora; [ela]; [ela]; a senhora } \\
\text { Gruwell; [ela]; ela; ela;a professora; }\end{array}$ & $\begin{array}{l}\text { seu entusiasmo, } \\
\text { dedicação e com } \\
\text { muita motivação; } \\
\text { sua (capacidade) }\end{array}$ & \\
\hline \multirow{2}{*}{ 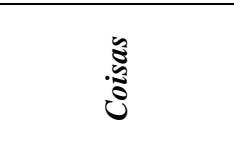 } & (4) Cidade & $\begin{array}{l}\text { chamada Long Beach; localizada nos } \\
\text { Estados Unidos; Nesta cidade }\end{array}$ & & \\
\hline & (5) Diários & $\begin{array}{l}\text { o Diário dos Escritores da Liberdade; } \\
\text { [os diários]; todas as suas histórias }\end{array}$ & & $\begin{array}{l}\text { (trabalhos) } \\
\text { parecidos }\end{array}$ \\
\hline
\end{tabular}

Figura 3 - Recursos para identificação de pessoas e coisas 
Além dos tipos de recursos mencionados para rastrear pessoas e coisas, é interessante observar também no texto, o recurso da referência textual, conforme exemplo (08):

(08) Enfim, tiveram a oportunidade de publicar o Diário dos Escritores da Liberdade que contava todas as suas histórias, inclusive a de que muitos foram os primeiros de suas famílias a entrarem em uma Faculdade, sendo grandes vitoriosos pelos desafios que percorrem até então. Isso foi tão significativo na vida destes alunos que até hoje, fazem trabalhos parecidos com outros jovens no Instituto dos Escritores da Liberdade e Fundação dos Escritores da Liberdade (T2_PED_SFP).

O termo "Isso" é uma referência que retoma toda a ideia anterior, destacada em itálico. Esse tipo de recurso é denominado por Martin e Rose (2007, p. 165) como referência textual. Em relação a este recurso, os autores afirmam:

Como nós temos visto ele é usado para organizar grandes significados de forma sintetizada, mais gerenciáveis, para que possamos, em seguida, produzir mais alguns significados com eles. Contração de significados, em outras palavras, para que novos significados possam ser expandidos. O texto vai fluindo assim como os argumentos se movem ao longo dele ${ }^{13}$.

A vantagem deste tipo de rastreamento é que trechos de significados podem ser recuperados por um termo que empacota uma porção de informações, o qual desempenha um novo papel no decorrer da argumentação, isto é, no desenrolar do texto. Usualmente, esta retomada é feita com os pronomes demonstrativos (este, esta, isso, isto). Esse tipo de referência é também conhecido como "encapsuladores", na perspectiva da referenciação (cf. APOTHÉLOZ, 1995; MONDADA E DUBOIS, 1995 e 2003), nos estudos da Linguística Textual.

\subsection{Tipos de referência}

Martin e Rose (2007, p. 169) afirmam que "Sempre que a identidade de um participante é presumida, essa identidade deve ser recuperada. Isso pode ser feito de várias formas dependendo de onde está a informação relevante". ${ }^{14} \mathrm{Na}$ escrita, segundo os autores, “o lugar para procurar uma identidade presumida está no entorno do texto" (MARTIN E ROSE, 2007, p. 169). ${ }^{15}$ Geralmente, olha-se para trás, como foi feito no Exemplo (08), mas é possível olhar para a frente, a fim de encontrar o que significa, considerar o conhecimento compartilhado entre escritor/leitor e analisar o contexto externo ao texto. A análise do contexto externo é relevante, pois algumas vezes a informação pode não estar no texto, mas fora dele em algum lugar. Considerando estes aspectos, Martin e Rose (2007) apresentam um esquema para Recuperar Identidades, conforme Figura 4: 


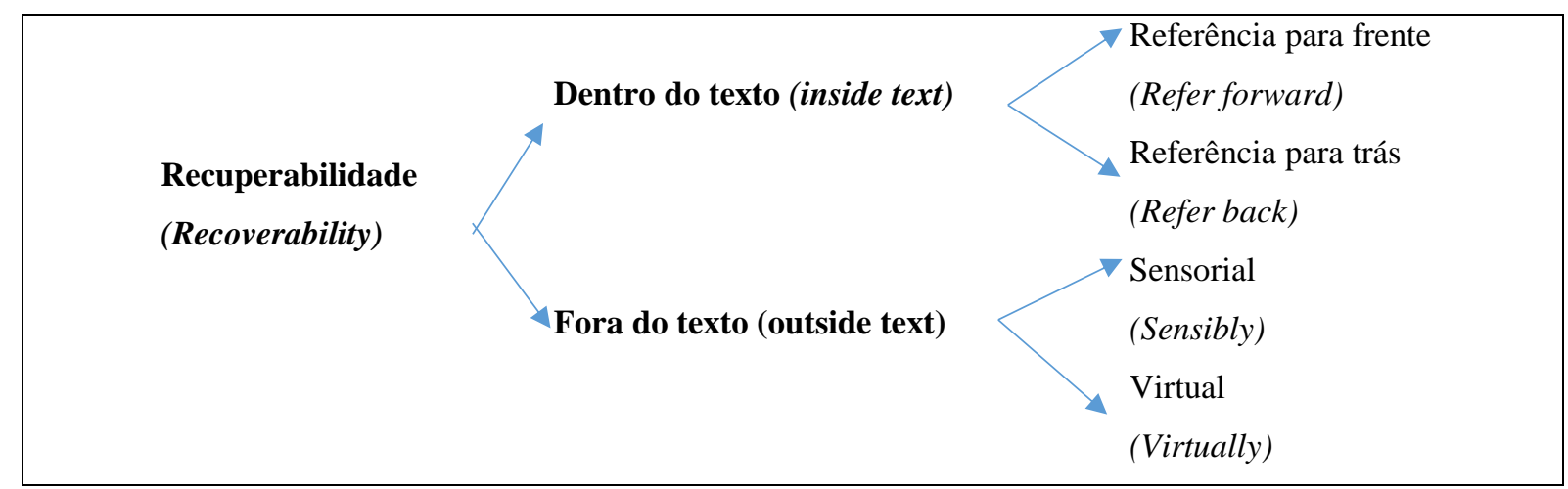

Figura 4 - Recuperação de identidades

Fonte: Adaptado de Martin e Rose (2007, p. 169).

Os autores destacam que a anáfora, a qual retoma um ponto que já foi mencionado anteriormente no texto, é o tipo de referência mais usado. A catáfora, por sua vez, é menos usada, sendo empregada ao referir-se a algo que será dito mais adiante. A catáfora é mais comum em discursos jurídicos e administrativos. Em (09), são exemplificadas as categorias mencionadas:

(09) A professora (1) não desiste. Ela (1) entra na realidade dos alunos (2) e consegue conquistar a atenção deles (2). Assim, consegue o que ninguém havia conseguido: despertar neles (2) a autoconfiança (3).

O termo "ela", identificado pelo número (1), em negrito, retoma o referente " $a$ professora", por meio de uma referência anafórica. O mesmo ocorre com os termos "deles" e “neles" em relação a "alunos”, identificados pelo número (2). Já a expressão "o que ninguém até então havia conseguido" não retoma nenhuma ideia apresentada anteriormente, pelo contrário, refere-se ao que será dito logo a seguir, identificado pelo número (3) e sublinhado "despertar neles a autoconfiança", ou seja, tem-se uma referência catafórica.

Em ambos os casos de referências mencionadas anteriormente, no exemplo (09), as identidades presumíveis encontram-se no texto verbal. No entanto, além desta situação, existem outros locais para procurar identidades, como salientam Martin e Rose (2007): fora do texto, ou seja, na cultura, no exterior e/ou na situação de fala. Essa informação pode ser encontrada no conhecimento cultural que o escritor e o leitor compartilham. O que pode ser observado quanto à referência, dos termos em destaque, no exemplo (10), a seguir:

(10) Então no decorrer do ano letivo as novidades que a senhora Gruwell preparava, mesmo sem apoio da direção escolar e de alguns professores, eram cada vez mais esperadas pelos alunos, mostrou que com carinho, companheirismo e atenção, eles tinham uns aos outros, assim como vimos nos capítulos estudados, como ser um bom professor e como ele deve de fato agir (T2_PED_SFP).

O grupo nominal "nos capítulos estudados" apresentado por um determinante definido $(\mathrm{em}+\mathrm{o})$ presume que tanto escritor quanto leitor saiba do que se trata, isto é, compartilham 
um conhecimento cultural a respeito. Esse tipo de referência, Martin e Rose (2007) classificam como homofórica.

Dentre os tipos de referências analisadas, a mais difícil de localizar é a referência exofórica, pois esta está fora do texto, ou seja, no contexto extralinguístico. O exemplo (11) ilustra uma situação de referência exofórica:

(11) Por fim, depois de toda essa análise do filme, [nós] vimos todos os processos dos capítulos que estudamos. Mostrando-nos que um bom professor, vai sim, aplicar, textos, matérias, mas vai também saber como aplicar, e como mudar a realidade dos alunos em sala de aula, aprendendo todos juntos (T2_PED_SFP).

A introdução de participantes no discurso no exemplo (11) é realizada por meio da elipse ou sujeito desinencial "[nós]"; esse termo diz respeito ao autor e à professora (sua leitora em potencial), podendo-se presumir ainda que este termo pode estar se referindo a todos os alunos da turma, ou seja, trata-se de uma referência exofórica, que está fora do texto.

Os tipos de referências mencionadas, anteriormente, voltam-se diretamente ao participante que é identificado. Martin e Rose (2007) mencionam que, embora seja possível observar alguns participantes que se pode presumir indiretamente, isso é menos comum. A estes os autores denominam de referência indireta ou referência ponte e ilustram com a seguinte passagem:

"Tshikalange esfaqueado primeiro. . . e ele não podia tirar a faca do peito de Mxenge"

O uso do termo "a faca" pressupõe uma referência presumida, uma vez que a coisa mais provável para alguém esfaquear outra pessoa é usando uma faca. Neste caso, o artigo definido " $a$ " estaria empregado adequadamente. No exemplo (12), é possível identificar uma anáfora indireta:

(12) Enfim, tiveram a oportunidade de publicar o Diário dos Escritores da Liberdade que contava todas as suas histórias, inclusive a de que muitos foram os primeiros de suas famílias a entrarem em uma Faculdade, sendo grandes vitoriosos pelos desafios que percorrem até então. Isso foi tão significativo na vida destes alunos que até hoje, fazem trabalhos parecidos com outros jovens no Instituto dos Escritores da Liberdade e Fundação dos Escritores da Liberdade (T2_PED_SFP).

Os termos "trabalhos parecidos" não possuem um referente direto no texto, mas se presume que estes estejam se referindo indiretamente aos diários que foram produzidos pelos alunos no decorrer do filme. Por fim, Martin e Rose (2007) trazem a referência esfórica, que é um recurso que identifica os participantes sem ser necessário olhar para outra parte do texto ou fora dele, pois os elementos simplesmente apontam para si mesmos. Isso acontece quando uma coisa modifica outra e responde à pergunta 'Qual?', como por exemplos em:

(13) a oportunidade de publicar (T2_PED_SFP).

(14) essa análise do filme (T2_PED_SFP). 
(15) a realidade dos alunos (T2_PED_SFP).

Em síntese, os tipos de referência propostos por Halliday e Matthiessen (2004) e Martin e Rose (2008) voltam-se à identificação e ao rastreamento do(s) referente(s), para os quais estes processos sugerem uma representação extensional de referentes do mundo, o que estabelece uma relação importante com a coesão e a coerência textual. Entretanto, para complementar a análise da progressão referencial, considerou-se relevante também explicitar como o sistema discursivo de periodicidade, que contempla a estrutura temática e a estrutura da informação, pode contribuir para a análise da progressão textual.

\section{Periodicidade: fluxo de informação}

Na Gramática Sistêmico-Funcional (GSF), dois sistemas paralelos e inter-relacionados de análise, são apresentados por Halliday e Matthiessen (2009; 2014). Esses sistemas envolvem a organização da mensagem em um texto: a estrutura da informação - nível do conteúdo -, que envolve os componentes denominados de informação dada e informação nova; e a estrutura temática - nível da oração -, que envolve as funções denominadas Tema e Rema. Para os autores, o Tema normalmente expressa a informação dada, a qual já é conhecida pelo ouvinte ou que é recuperável no contexto, enquanto o Rema, por sua vez, "expressa a informação nova: aquela que o ouvinte desconhece, e que corresponde, efetivamente, ao conteúdo que se deseja que ele passe a conhecer" (VENTURA E LIMALOPES, 2002, p.01). Logo, especialmente, na escrita, é importante perceber essa relação entre a escolha lexicogramatical e a organização temática das orações, uma vez que os sujeitos não podem utilizar a entonação para marcar quais informações são mais relevantes e quais ficariam em segundo plano.

Martin e Rose (2007, p. 188) postulam que "a periodicidade se relaciona com o fluxo de informação - o modo pelo qual os significados são empacotados para serem melhor entendidos por nós [leitores]". ${ }^{17}$ Por meio deste sistema, procura-se dar ao leitor/ouvinte (uma ideia do que será tratado no texto, preencher as expectativas e revisá-las. Assim, o fluxo discursivo agrupa as porções de mensagens, que formam as fases do discurso, sendo assim denominado por Martin e Rose (2007) como periodicidade.

Seguindo Halliday (1978), Martin e Rose (2007) têm utilizado o movimento de onda como metáfora para as fases do discurso e/ou para descrever este tipo de fluxo de informação: uma sucessão de pequenas ondas de informação constitui uma onda maior, em sucessão, formam ondas maiores ainda. Em outras palavras, como salientam Martin e Rose (2007, p. 
189), diferentes tipos de ondas possibilitam que o texto tenha um ritmo, isto é, "tenha uma batida; e sem este ritmo, seria muito difícil entendê-lo"18. Do ponto de vista do significado textual, como é tratado por Halliday, há duas ondas que se sobrepõem: uma onda temática, com o pico mais proeminente no início da oração, chamado de Tema; e uma onda nova com um pico no fim da oração chamado Novo.

A escolha mais comum para o Tema da oração é o sujeito denominado de Tema nãomarcado. Quando se escolhe trazer para o início da oração uma circunstância de lugar ou tempo, ou outro participante que não seja sujeito, tem-se o Tema marcado, que é usado para sinalizar uma nova fase do discurso. Na outra ponta da oração, tem-se o que Halliday chama de "Novo". Para Martin e Rose (2007, p. 192), "as escolhas de Novo são muito mais variadas do que as escolhas por Temas não-marcados. Elas captam o interesse humano, assim como as escolhas por Temas não-marcados tendem a chamar nossa atenção". ${ }^{19}$

O empacotamento do discurso como escolhas de Tema e Novo, vistos em cada oração, é refletido pela padronização em escala maior das fases de discurso. Estes padrões predizem o que vai acontecer em cada fase do discurso e refinam a informação nova que cada uma das fases apresenta. São denominados de hiperTema e hiperNovo, e aparecem no texto para indicar ao leitor de onde se parte e para onde se vai, como salientam Martin e Rose (2007, p. 195): "HyperThemes nos dizem onde estamos indo em uma fase; hiperNews nos dizem onde nós estivemos". 20

Os autores também exploraram o Tema em níveis acima da oração, além dos conceitos de hiperTema e hiperNovo, propõem os conceitos macroTema e macroNovo. Todos esses conceitos inserem-se em uma perspectiva discursiva na qual o fluxo de informação apresenta uma regularidade e um ritmo que auxiliam o(a) leitor(a) a compreender melhor o texto metáfora das ondas, o que pode ser observado na Figura 5.

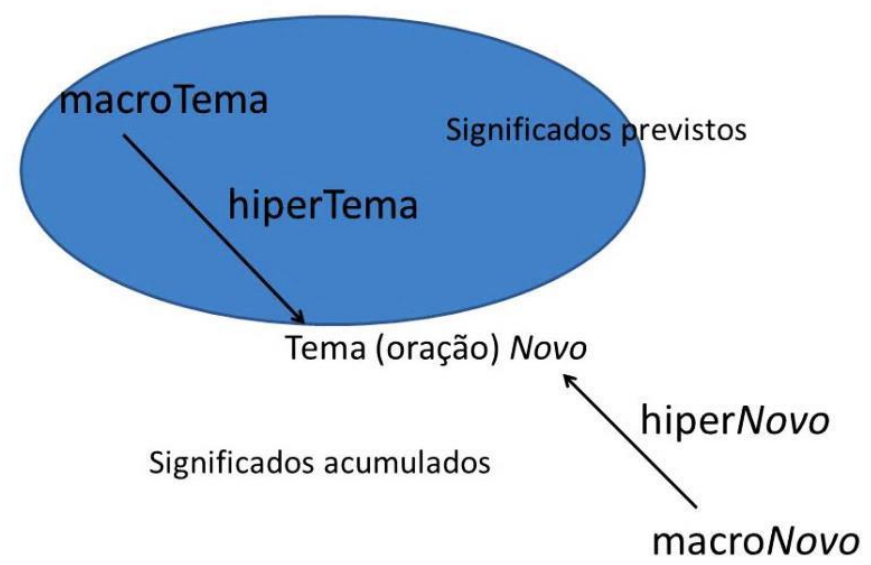

Figura 5 - Estratos de Tema e Novo no discurso 
Fonte: Adaptado de Martin e Rose (2007, p. 36).

O hiperTema localiza-se em um nível acima do Tema, nas palavras de Martin e Rose (2007, p. 194): “pode-se tratar esta 'sentença tópica' como uma espécie de nível superior Tema: um hyperTheme", ${ }^{21}$ o qual estabelecerá expectativas de como o texto irá se desenvolver. Conforme descrevem Martin e Rose (2007), ele pode ser representado pela oração que apresenta o tópico ou por uma sentença tópico, que anuncia como será o desenrolar da informação a partir de então.

O hiperNovo, por sua vez, relaciona-se ao acúmulo de informação nova que frequentemente surge em uma sentença que faz um retrospecto do que aconteceu nos parágrafos anteriores. Deste modo, o hiperNovo proporciona uma nova finalidade ao texto: "a informação se acumula em cada oração à medida que a fase se desenrola. Em textos escritos particularmente, esta acumulação de novas informações é muitas vezes destilada numa sentença, que assim funciona como um hiperNovo para a fase" ${ }^{22}$. Os Temas localizados em um nível acima dos hiperTemas são chamados de macroTemas. Já a informação nova que se localiza em um nível acima do hiperNovo é chamada de macroNovo. Tanto o macroTema quanto o macroNovo ocorrem quando há uma complexidade das fases de informação em um texto (MARTIN e ROSE, 2007).

O exemplo (16) ilustra essa relação:

(16) $\mathrm{O}$ artigo faz uma reflexão agroecológica, que critica o atual sistema de agricultura convencional, e traz com isso a ciência agroecológica como uma inovadora alternativa de produção. O público alvo do artigo são agricultores, estudantes de ciências agrárias e empresas que comercializam insumos agrícolas. $\mathrm{O}$ tema abordado é muito pertinente a ser estudado no contexto em que o curso de Agronomia se insere.

$\mathrm{O}$ artigo foi organizado em quatro seções. A primeira seção, com o título de introdução, trata das ideias iniciais, em torno da agroecologia e como se deu a constituição deste novo paradigma agrícola, e também buscou caracterizar a agricultura convencional, com as adoções de tecnologias, desigualdade social, e praticas não conservacionista, e quais suas consequências, e com isso colocando a agroecologia como um fator determinante para a invocação da sustentabilidade para sistemas agrícolas (BALESTRIN, 2016). A segunda seção traz o título de: Agricultura e sustentabilidade, um desafio para o século XXI. Nesta seção é trazido um comparativo, entre os sistemas produtivos de base convencional e $\underline{\text { agroecológica, elencando os impactos criados pelo sistema convencional dentro dos }}$ agroecossistemas, no meio ambiente e também aos humanos. Apontando assim como se deu o impulso principal, para se difundir a sustentabilidade produtiva, e a diferenciação existente entre os dois modelos produtivos abordados. A terceira seção, com o título de: Agroecologia: um novo paradigma retrata como se faz a construção desta nova proposta produtiva sustentável. Essa nova proposta agroecológica, traz um novo exemplar agrícola, colocando o agricultor como ator principal, fazendo sua atuação de extrema importância, tendo ação ativa nos diversos componentes do agroecossistema. Como resultado dessa nova relação do $\underline{\text { agricultor com o agroecossistema, ele passa a desenvolver práticas conservacionistas }}$ 
sustentáveis para produzir, trazendo um maior equilíbrio para o ecossistema envolvido (T3_AGRO_TP).

Em (16), a evolução do fluxo da informação se dá por meio da relação que se estabelece entre os macroTemas, destacadas em negrito, e os hiperTemas, que estão sublinhados. Os hiperTemas se colocam abaixo dos macroTemas, mas acima dos Temas. Essa relação se estabelece mais no nível semântico do que no nível lexicogramatical e estrutural. Percebe-se que os macroTemas apresentam um certo empacotamento da ideia que será abordada a seguir, ou seja, anuncia como será o desenrolar da informação a partir de então, semelhante a relação que acontece entre o Tema das orações, que sinalizam o que virá a seguir (cf. MARTIN; ROSE, 2007). Salienta-se, porém, que essa relação existente entre macroTemas e hiperTemas não pode ser localizada estruturalmente no texto, como é o caso do Tema da oração. No entanto, essa relação hierárquica existente entre os Temas das orações configura-se em um processo de referenciação semântico-discursiva, que contribui significativamente para a progressão do fluxo da informação no texto, juntamente com a estrutura sintático-semântica analisada por meio do sistema discursivo de identificação.

Por fim, quanto aos sistemas discursivos de identificação e periodicidade, pode-se concluir que (1) a identificação de como se dá a introdução e o rastreamento dos participantes nos textos selecionados permitiu constatar os principais tipos de referências que fazem parte das escolhas discursivas e lexicogramaticais dos alunos do primeiro semestre da graduação, bem como permitiu verificar como a progressão referencial contribui para a progressão textual e para que o fluxo de informação do texto; (2) os recursos anafóricos diretos predominam nos cinco textos. Esse padrão discursivo explicita que os alunos preferem recorrer às estratégias mais conhecidas ou que fazem parte do seu conhecimento implícito sobre os processos de referenciação; (3) as referências textuais ou anáforas encapsuladoras que contribuem para a continuidade lógica e argumentativa do texto apareceram apenas esporadicamente nos textos que constituem o corpus, deixando em evidência uma dificuldade que os alunos possuem no manejo da língua escrita. (4) os resultados da análise dos textos evidenciam a importância de se apropriar do conhecimento referente às variáveis de registro contexto de situação - e do gênero - contexto de cultura, para compreender as escolhas que se dão nos estratos semântico-discursivo e lexicogramaticais; (5) pelos tipos de referências e estrutura temática presentes nos textos, pode-se concluir que os alunos têm um conhecimento implícito destas estratégias de construção textual, no entanto é evidente a necessidade de se 
trabalhar com estas questões de forma mais sistêmica, contribuindo assim para o aprimoramento do letramento acadêmico.

\section{Considerações Finais}

O presente estudo teve como objetivo explicitar os sistemas discursivos de identificação e periodicidade, a fim de compreender a organização textual numa perspectiva sistêmico-discursiva. Nesse sentido, pode-se evidenciar o quanto a referência e organização temática influenciam no desenvolvimento do texto, pois além de permitir ao autor colocar em destaque determinadas informações, ajuda na construção de sentidos e dá pistas de como estas informações fluem no texto.

A análise do sistema de identificação permitiu constatar os principais tipos de referências que fazem parte das escolhas discursivas e lexicogramaticais dos alunos do primeiro semestre da graduação por meio da análise da introdução e do rastreamento dos participantes nos textos selecionados. Os recursos anafóricos diretos foram os mais utilizados. Padrão este que explicita a preferência dos alunos recorrerem às estratégias mais conhecidas ou que fazem parte do seu conhecimento implícito sobre os processos de referenciação. Já as referências textuais ou anáforas encapsuladoras, características de textos acadêmicos, apareceram apenas esporadicamente, evidenciando uma dificuldade apresentada pelos sujeitos da pesquisa no manejo da língua escrita.

Os resultados deixaram também em evidência a importância de se considerar o conhecimento referente às variáveis de registro - contexto de situação - e do gênero contexto de cultura, para compreender as escolhas que se dão nos estratos semânticodiscursivo e lexicogramaticais dos textos. Tal recurso passa muitas vezes despercebido por escritores iniciantes.

A análise do sistema de periodicidade contemplando a relação Tema/Rema e as porções de mensagens agrupadas para formar as fases do discurso permitiu delinear o fluxo discursivo e a progressão temática dos textos que constituíram o corpus desta pesquisa. Com isso, conclui-se que a progressão referencial e a progressão temática contribuem para a organização e progressão textual, garantindo o fluxo da informação no texto.

As categorias propostas para analisar os processos semântico-discursivos de identificação e periodicidade, constituem uma possibilidade a mais para compreensão do funcionamento da linguagem em uso. Pode-se afirmar que os alunos têm um conhecimento implícito dessas estratégias de construção textual, no entanto é evidente a necessidade de se 
trabalhar com estas questões de forma mais sistêmica, explorando as potencialidades da linguagem, a fim de contribuir com o letramento acadêmico. Assim, espera-se por meio deste estudo despertar o interesse de mais estudiosos e pesquisadores da área, principalmente daqueles que atuam no ensino superior, a fim de contribuir na superação das dificuldades que os alunos, principalmente dos semestres iniciais, apresentam quando se deparam com a escrita acadêmica.

\section{REFERÊNCIAS}

APOTHÉLOZ, D. "Nominalisations, réferents clandestins et anaphores atypiques". In: BERRENDONNER, A. e M-J REICHLER-BEGUELIN (eds). Du sintagme nominal aux objets-dediscours. Neu châtel: Universitê de Neuchâtel, 1995, pp. 143-173.

Les formulations collaboratives du texte dans une rédaction conversationnelle: modes d'expansion syntaxique, techniques métalangagières, grandeurs discursives manipulées, etc. In: BOUCHARD, R.; DE GAULMYN, M.-M.; RABATEL, A. (éds). Le processus rédactionnel. Ecrire à plusieurs voix. Paris: L'Harmattan, 49-66, 2001.

APOTHÉLOZ, D.; CHANET, C. Definido e demonstrativo nas nomeações. In: CAVALCANTE, M., BIASI-RODRIGUES, B; CIULLA, A. (orgs.) Referenciação. São Paulo: Contexto, 2003, p.131-76.

BOGDAN, R.; BIKLEN, S. Investigação Qualitativa em Educação. Portugal Porto: Porto Editora, 1994.

CEP/UFRGS - Comitê de Ética em Pesquisa da UFRGS. http://www.ufrgs.br/cep/. Acesso em 20 jun.2017.

CHAROLLES, M. Associative anaphora and its interpretation. Journal of Pragmatics. vol.31., $\mathrm{n}^{\circ} 3$, 1999, p.307-10.

EGGINS, S. An Introduction to Sistemic Functional Linguistics. London: Pinter, 1994.

. An introduction to systemic functional linguistics. Londres: Pinter Publishers, 2004.

HALLIDAY, M. A. K. Language as social semiotic. London: Edward Arnold, 1978.

. ; MATTHIESSEN, C. An introduction to functional grammar. London: Hoder Education, 2004.

Systemic functional grammar: A first step into the theory. (2009). Disponível em: https://www.researchgate.net/profile/Christian_Matthiessen/publication/265398862_SYSTEMIC_FU NCTIONAL_GRAMMAR_A_FIRST_STEP_INTO_THE_THEORY/links/54b513ef0cf28ebe92e4ba cf.pdf, Acesso em 10 de mar. de 2018.

. An introduction to functional grammar. London: Arnold, 2014.

HALLIDAY, M. A. K; HASAN, R. Cohesion in spoken and written English. Londres: Longman, 1976.

. Cohesion in English. London: Longman, 1985.

MARTIN, J. R. English text - systems and structure. Philadelphia: Amsterdam: John Benjamins Publishing Company, 1992. 2007.

; ROSE, D. Working with discourse: meaning beyond the clause. $2^{\text {nd }}$ ed. London: Continuum,

MOITA LOPES, L. P. Oficina de Linguística Aplicada. Campinas: Mercado Aberto, 2001.

MONDADA, L. Pour une approche conversationnelle dês objets de discours. Boletim da ABRALIN, v. 26, n.esp., p.66-70, 2001.

A referência como trabalho interativo: a construção da visibilidade do detalhe anatômico durante uma operação cirúrgica. In: KOCH, I. V.; MORATO, E. M.; BENTES, A. C. (Org.). Referenciação e discurso. São Paulo: Contexto, 2005. p. 11-31. 
MONDADA, L.; DUBOIS, D. Construction des objets de discours et catégorisation: une approche des processus de référenciation. In: TRANEL (Travaux Neuchâtelois de Linquistique), n.23, 1995, p.273302. Tradução para o português: Construção dos objetos do discurso e categorização: uma abordagem dos processos de referenciação. In: CAVALCANTE, M. M.; RODRIGUES, B. B.; CIULLA, A. (orgs.) Referenciação. São Paulo: Contexto, 2003, p.17-52.

NUNES, L. P. As conjunções but e mas em textos ficcionais originais e traduzidos: uma análise tridimensional com base na linguística sistêmico-funcional. Belo Horizonte: UFMG, 2010. 106 f. Dissertação (Mestrado em Linguística Aplicada). Programa de Pós-Graduação em Estudos Linguísticos da Faculdade de Letras da Universidade Federal de Minas Gerais, Belo Horizonte, 2010. ROSE, D.; MARTIN, J. R. Learning to write, reading to learn: Genre, knowledge and pedagogy in the Sydney School. Equinox, 2012.

THOMPSON, G. Introducing functional grammar. 3rd ed. New York: Routledge-Taylor \& Francis Group. 2014.

VIAN JR., O; IKEDA, S. N. O ensino do gênero resenha pela abordagem sistêmico-funcional na formação de professores. In: Linguagem \& Ensino, Pelotas, v.12, n.1: jan./jun, 2009. p. 13-32.

O ensino do gênero resenha pela abordagem sistêmico-funcional na formação de professores. Revista Linguagem \& Ensino, v. 12, n. 1, p. 13-32, 2012.

VIAN JR., O; MENDES, W. V. O sistema de conjunção em textos acadêmicos: os mecanismos de sequenciamento e de explicação. In: CABRAL, S.R.S.C; BARBARA, L. Estudos sistêmicofuncionais: desdobramentos e interfaces. Letras, n. 50, v. 25, jan./jun., 2015, p. 163-186.

\footnotetext{
${ }^{1}$ O contexto, para Halliday (1999), é considerado um conceito-chave na LSF, uma vez que situa o texto em relação à situação de produção mais imediata, contemplada pelo contexto de situação, e também de forma mais abrangente, contemplada pelo contexto de cultura.

${ }^{2}$ Com aprovação do CEP/UFRGS, conforme Parecer consubstanciado $\mathrm{n}^{\circ} 1.662 .694$.

${ }^{3}$ No original: "There are certain items in every language which have the property of reference, in the specific sense in which we are using the term here; that is to say, instead of being interpreted semantically in their own right, they make reference to something else for their interpretation".

${ }^{4}$ Os exemplos usados neste estudo são fragmentos de textos produzidos por alunos do primeiro semestre da graduação, aqui identificados como Texto 1 (T1_PED_SFP), Texto 2 (T2_PED_SFP), Texto 3 (T3_AGRO_TP), Texto 4 (T4_PED_OSO) e Texto 5 (T5_GA_TP).

${ }^{5}$ Para uma descrição sistemática deste processo de identificabilidade como um sistema semântico-discursivo, Halliday e Matthiessen (2004) indicam ver Martin (1992).

${ }^{6}$ No original: "[...]is concerned with tracking participants - with introducing people and things into a discourse and keeping track of them once there. These are textual resources, concerned with how discourse makes sense to the reader by keeping track of identities".

${ }^{7}$ Quando o termo "apresentação" for usado no texto referindo-se à categoria do sistema discursivo de identificação será grafado em itálico: "apresentação", bem como as demais estratégias, tais como a de rastreamento de participantes e a de referenciação.

${ }^{8}$ A indicação numérica foi usada para facilitar a identificação dos referentes, conforme segue: (1) jovens, (2) Eva, (3) Erin Gruwell, (4) cidade e (5) os diários.

9 Embora o texto apresente problemas de escrita, estas não são comentadas nesta seção, pois o propósito é apenas exemplificar os tipos de identificação e referências apresentados.

${ }^{10}$ No original: "(...) makes it possible to leave out parts of a structure when they can be presumed from what has gone before".

${ }^{11}$ No original: “(...) speakers/writers make assumptions on the go about what listeners/readers can and can't be expected to know. If someone's identity is as good as given then presuming reference is used, even where that character hasn't been mentioned before"

${ }^{12}$ No original: "My story begins my late teenage years as a farm girl..."

${ }^{13}$ No original: "As we've seen it is used to turn big meanings into smaller, more manageable ones, so that we can then make some more meanings with them. Meanings contract, in other words, so that new meanings can expand. The text is breathing, as the argument moves along".

${ }^{14}$ No original: "Whenever the identity of a participant is presumed, that identity has to be recovered. This can be done in various ways depending where the relevant information is".

${ }^{15}$ No original: "In writing, the obvious place to look for a presumed identity is the surrounding text".

${ }^{16}$ No original: "Tshikalanga stabbed first ... and he couldn't get the knife out of the chest of Mxenge"

${ }^{17}$ No original: "Periodicity is concerned with information flow - with the way in which meanings are packaged to make it easier for us to take them in".

${ }^{18}$ No original: "(...) has a beat; and without this rhythm, it would be very hard to understand".

${ }^{19}$ No original: "(...) the choices for New are much more varied than the choices for unmarked Theme. They elaborate with human interest, whereas choices for unmarked Theme tend to fix our gaze".
} 
${ }^{20}$ No original: "HyperThemes tell us where we're going in a phase; hyperNews tell us where we've been".

${ }^{21}$ No original: "(...) we can treat this 'topic sentence' as a kind of higher level Theme: a hyperTheme”.

${ }^{22}$ No original: “(...) new information accumulates in each clause as the phase unfolds. In written texts in particular, this accumulation of new information is often distilled in a final sentence, that thus functions as a hyperNew to the phase".

Recebido em 27/03/2018. Aceito em 06/06/2018. 